\title{
Filipino Adolescents' Experiences of Abusive Parent-Child Relationship in Low Socioeconomic Status Families
}

\author{
Jess Sabarre ${ }^{1} 8$ (D). Paulo Louis H. Villareal ${ }^{2} 8$ (D) and Dr. Myla M. Arcinas ${ }^{3} 8$ (D) \\ ${ }^{12}$ Integrated School, De La Salle University, Manila, Philippines \\ ${ }^{3}$ Behavioral Sciences Department, De La Salle University, Manila, Philippines \\ $\triangle$ Corresponding Author: Dr. Myla M. Arcinas, E-mail: myla.arcinas@dlsu.edu.ph
}

\author{
ARTICLE INFORMATION \\ Received: March 14, 2021 \\ Accepted: April 02, 2021 \\ Volume: 3 \\ Issue: 4 \\ DOI: $10.32996 /$ jhsss.2021.3.4.2
}

\section{KEYWORDS}

Abusive parent-child relationship, Physical Abuse, Verbal Abuse, Social Support System, Coping Mechanism, Family, Adolescent

\section{ABSTRACT}

This phenomenological-qualitative study aimed to describe how an abusive parentchild relationship of selected Filipino adolescents from an intact family of low socioeconomic status affects the perceptions of their potential romantic partner, marriage, and family. The study also uncovered their coping mechanisms and support system. The seven informants were identified using a purposive sampling technique. The researchers devised an open-ended interview guide to elicit information from the informants and were conducted with a guidance counsellor. With the use of content analysis, the study revealed that their abusive experiences with one or both parents have significantly affected their perceptions. Most of them have resorted to using negative coping strategies and that their grandparents stood as their extended family support system with their friends as their non-family support system. The informants displayed a significantly entrenched position on the characteristics of their future marital partner and family. However, they have shown disapproval of marriage due to their experiences. The study also exposed that mothers have been more present in the abusive parent-child experiences than the fathers, which contradicts expectations that fathers act as strict disciplinarians and mothers being the child's protector in Philippine Culture. The study exposed the experiences of children in verbal and physical abuse in their homes from intact families with low socioeconomic status in Metro Manila, wherein expounds on the type of social support these children have been given and the kinds of coping mechanisms that are prevalent in their experiences and how these abusive parent-child experiences reflected with either positive or negative on their perception of marital partner, the concept of marriage, and concept of family, wherein provides substantial knowledge on how these experiences can be handled and faced in terms of treatment.

\section{Introduction}

Children flourish in predictable, stable, and nurturing environments. However, rapid and sudden disturbances and changes may be highly traumatic for children in some circumstances, affecting their emotions and security. At the same time, extremes can be harmful to children's mental health and cognitive functioning (Evans et al., 2011). These disturbances also prove to be one of the most damaging consequences of an abusive parental-child relationship, which is a widespread problem affecting adolescents in many aspects of their lives, especially physically, educationally, and professionally regarding the relationship of those involved. Also, abused and neglected children and adolescents are more likely to have poor long-term health, compromised mental health, and adverse social effects than those not exposed to abuse and neglect, according to the US Centers for Disease Control and Prevention.

Physical and emotional child abuse and neglect have been related to a wide variety of long-term health concerns, such as depression, anxiety, opioid use, suicide attempts, and sexually transmitted infections (Li et al., 2016). The importance of

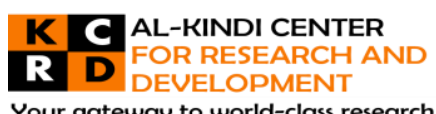

Your gateway to world-class research

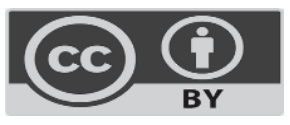

Published by Al-Kindi Center for Research and Development. Copyright (c) the author(s). This open access article is distributed under a Creative Commons Attribution (CC-BY) 4.0 license 
identifying and mitigating the possible risk factors of child abuse is highly relevant in decreasing the risk of dysfunctional, abusive, and neglectful parenting. Unmet needs create a health care crisis for children with mental health issues and their families (US Department of Health and Human Services, 2001).

Family violence may be more common in the parent-child relationship due to this start-up, allowing for specific abusive techniques to manifest in daily interactions. However, "adolescent behavior" is expected in a child's development that can include similar behaviors that serve the parent-child relationship's power hierarchy. Therefore, it is highly relevant to recognize the pattern of aggression and how it becomes abusive to the child. Physical abuse has been brutal to describe due to the difficulty of determining what constitutes excessive or insufficient child punishment.

In such situations, socioeconomic status may affect a child's growth and development, with poor children experiencing emotional and behavioral issues at a higher rate than non-poor children, with externalizing behaviors like violence, harassment, and acting out, as well as internalizing behaviors like anxiety, social isolation, and depression (Brooks-Gunn \& Duncan, 1997). Poverty has been related to lower-quality parent-child relationships and increased use of extreme punishments and discipline, such as spanking, according to research. Low-income parents have poor mental and physical health, which leads to strained parent-child relationships and fewer opportunities for learning at home. A child's home environment is also considered to significantly impact young children's cognitive and emotional outcomes.

This study is limited only to the recalled abusive parent-child experiences focusing on physical and verbal abuse among selected Filipino adolescents (ages 18 - 24) from intact families of low socioeconomic status in Metro Manila. The study used a qualitative methodological approach in a phenomenological tradition through key informant interviews (KII) in unpacking and describing their social support system experiences, coping mechanisms, and their perceptions of future marital partners, concepts of marriage, and concepts of family based on their abusive experiences.

The study will only accommodate seven (7) informants who strictly have passed the researchers' pre-selection criteria. The study will not accommodate informants from a non-intact family or middle to high socioeconomic status.

\section{Literature Review}

\subsection{Abusive Parent-Child Experiences}

According to the Republic Act (RA) 9262 or the Anti Violence Against Women and their Children act of 2004 of the Philippines, by definition refers to any action or a series of acts committed by any person against a woman who is his wife, former wife, or against a woman with whom the person has or had a sexual or dating relationship, or with whom he has a typical child, or against her child whether legitimate or illegitimate, within or without the family abode, which result in or is likely to result in physical, sexual, psychological harm or suffering, or economic abuse including threats of such acts, battery, assault, coercion, harassment or arbitrary deprivation of liberty. Healthy parenting includes concerns about growth and development, child behavioural and social issues, emotional well-being, and financial responsibilities. These concerns alone can result in parental distress (Ross \& Blanc, 1998); therefore, it increases parental difficulty significantly and may lead to a family crisis influenced by unfortunate and unrestricted reasons. With the constant disagreement between parents during the childhood years of a child, the stress can become persistent and violent, which leads to physical and verbal parent-child abuse that will ultimately affect the family administration. Therefore, this turn of events is more devastating on developing the child's behavior and ability to have sound decision-making and influence social and personal relationships to oneself (Saikia, 2017).

Any global approach to a parent-child dysfunctional relationship must consider the various parenting patterns and expectations across cultures (WHO, n.d). Culture contributes to the development of widely accepted child-rearing and child-care values. Different societies have their own set of guidelines on what constitutes appropriate parenting conduct. According to some scholars, cultural perspectives on child-rearing can diverge to the point that consensus on neglectful practices can be challenging to achieve. However, cultural variations on how abuse is defined have much to do with stressing specific parental conduct aspects. There seems to be widespread consensus in many societies that child violence should not be tolerated, with near-unanimity when it comes to harsh disciplinary procedures and sexual abuse (WHO, n.d.). Official reports also show little about child violence trends. This is partly because, in many countries, there are no legal or social structures in place to document, much less react to, allegations of child abuse and neglect (Bross, 2000). Also, different countries have different legal and cultural concepts of violence and neglect. Even where mandatory reporting is in place, there is proof that only a small percentage of child maltreatment reports are reported to authorities (Theodore et al., 1999).

\subsection{Physical Abuse}

Physical abuse is widely described as a parent-initiated act that results in non-accidental injury and the infliction of overt physical violence (e.g., Kelly, 1983; National Center on Child Abuse and Neglect [NCCAN], 1988; Wolfe, 1988). Physical abuse typically 
occurs in isolated, low-frequency episodes and is often accompanied by irritation and anger directed at the infant (Kelly, 1983). Beating, rubbing, burning, lacerating, suffocating, blinding, poisoning, exposure to excessive heat or cold, sensory overload (e.g., extreme light, sound, stench, aversive taste), and sleep deprivation are all forms of physical violence. There is no straight line between what constitutes permissible physical punishment and what constitutes violence. Definitions of abuse in state statutes vary significantly in particularity (Besharov, 1990; Kalichman, 1993). The legal descriptions are often too vague to have applied research implications but are sufficiently general to prevent cases from slipping through the legal system's technicalities.

Child physical abuse warrants clinical and empirical attention because of the risks to a child's immediate safety and long-term developmental course and psychological adjustment. Several research studies have examined the characteristics of abused children. Maltreated children have been found to show more significant perceptual-motor deficits; lower scores on measures of general intellectual functioning; lower scores on academic achievement tests; insecure attachments; internalizing psychological problems, such as feelings of hopelessness, depression, and low self-esteem; and malicious social behavior, such as more aggression with adults and peers (Ammerman et al., 1986).

In some instances, children's physical violence can take many forms, constituting "crossing the line" from discipline to child abuse and resulting in several consequences (Corso et al., 2008). A study by Rerkswattavorn \& Chanprasertpinyo in 2019 focused on rural Thailand that represents the general population of low-income countries has shown that religion, culture, beliefs, and ethnic customs strongly influence their daily life; thus, child discipline in the form of physical and verbal abuse is accepted and passed down from generation to generation. They found that physical and verbal abuse was widespread in their study, and spanking by hand was the most common method of physical abuse, and yelling was the most commonly vocal abuse method. Over $95 \%$ of subjects had experienced or practiced physical and verbal abuse in their daily lives. These findings are consistent with a previous study by Lansford et al. (2010), demonstrating that child abuse is a common problem in developing countries.

\subsection{Verbal Abuse}

Regardless of how it is perceived, the fact remains that verbal violence may harm a victim's psychological and mental health. Even if the scars are not noticeable, the seriousness of the situation is critical, mainly when the victim is a child who will have to bear the wounds until adulthood (Che Noh et al., 2012). Grady (2003) defines verbal abuse as "words that attack or harm a person, words that cause one to believe an untrue argument or words that falsely speak of an individual." Since wounds are seldom noticeable unless physical abuse has happened, verbal abuse is also more challenging to identify. Although verbal abuse leaves no visible trace or evidence, a verbally abused survivor typically suffers from low self-worth and esteem (Che Noh et al., 2012). Grady (2003) also claims that verbal abuse is worse than physical abuse because it is considered a psychological assault. It is much more insidious because it targets both the emotional and mental dimensions of the victim. This is reinforced by Brendgen et al. (2006), who found that verbal abuse can be categorized as part of the broader definition of children's psychological abuse or maltreatment. Also, according to Garbarino et al. (1986), verbal abuse is "emotional abuse, an assault on a child's growth of self and social maturity, and a pattern of psychically harmful behavior."

Standing on the same ground is Keller (2009), who finds that child behavior problems were related to parental use of verbal and corporal punishment and were detrimental to the parent-child relationship's quality. According to Spillane-Grieco (2000), criminal offender teenagers, who rated themselves for aggression, both physical and verbal, disclosed the excessive use of verbal abuse in their families. Although the loss or injury suffered by a verbal abuse child victim cannot be precisely quantified, such abuse's effects are not to be brushed aside. A child victim suffering from verbal abuse may lose his childhood; as observed by Vachss (1994), visible scars cannot measure emotional abuse costs, but each victim loses some percentage of capacity (Che Noh et al., 2012).

\subsection{Social Support Systems}

It is often stated in the literature that the differences in the timing of disclosure may result due to various factors, such as personal reasons, family influences, existing family dynamics, emotional bond, cultural norms, and aspects concerning the perpetrator (e.g., grooming behaviors, the relationship between the victim and the perpetrator, feeling loyalty toward the offender) (Bennett et al., 2014; \& Dolev-Cohen et al., 2020). The most common variables related to the timing of disclosures in abuse include the perpetrator-victim relationship, family support, and variables measuring the severity of the physical and verbal abuse. Victims may immediately report or prolong telling the abuse according to their perceived social support level of their family and community, or the person to whom they decide to disclose the abuse may change (Koçtürk et al., 2020). It is of utmost importance for the victim, even in infancy, to perceive a high level of social support following the disclosure of abuse for a better psychosocial adjustment (Elliott et al., 2001; Kogan, 2005; Ullman, 2002). Therefore, identifying the barriers to abuse disclosure is highly significant, encouraging the victims to report the abuse immediately, determine probable familial and social factors hindering social support, give suitable responses to victims, and mitigate the abuse's negative effect on them. Although many parenting programs are shown to help child discipline and child abuse prevention, they are most practical in high-income 
countries. To date, the research on parenting program effectiveness in low-income countries is limited (Mejia et al., 2012). In lowincome countries, cultural beliefs and values might preserve the use of harsh parental discipline as a form of child discipline; therefore, the parenting program is essential for developing knowledge, skills, and awareness to prevent child discipline from becoming child abuse (Rerkswattavorn \& Chanprasertpinyo, 2019).

\subsection{Coping Mechanisms}

A coping mechanism is a goal-oriented process in which individuals direct their thoughts and behaviors toward resolving the source of stress and managing reactions to the stressor (Jackson et al., 2017); it refers specifically to regulatory efforts consciously used in response to stress (Compas et al., 1999). Dimensions of coping that aim to represent the overarching characteristics of responses to stress include problem-focused coping and emotion-focused coping and have been used readily throughout the youth managing literature (Browne, 2002; Carlo et al., 2012; Jackson et al., 2017). Responses considered problemfocused coping can include seeking solutions to the stressor and taking actions to alter the stressful situation. Emotion-focused coping can consist of expressing emotions or using emotions to seek others' support (VanMeter et al., 2020). Seiffge-Krenke \& Klessinger (2000) emphasized that how children cope with stress is related to their mental well-being. Children, particularly young children, might not have the tolerance to handle stressful situations and thus avoid these situations as a form of protecting stress systems; with time and opportunity, a youth's coping style is more likely to be a product of the demands in their environment, requiring the development of more skills (Seiffge-Krenke \& Klessinger, 2000). Therefore, repeated exposure to extreme stress and lack of exposure to healthy, alternative coping models might solidify maladaptive coping strategies. Coping strategies play an important factor in mediating the pathway between a history of maltreatment and the development of internalizing and externalizing symptoms in children (VanMeter et al., 2020).

\subsection{Filipino Families}

Family is functionally defined as a unit visible of the sharing of resources and commercial property, a caring and supportive relationship, commitment to or identification with other family members, and preparation of children born to or raised by the members to become adult members of the society (Purdue University, n.d.). In most cultures, parenting is seen as an integral social role with a significant influence on the lives of children and parents themselves (Alampay, 2014). Family in the Philippines is deemed essential and is particularly highlighted in Philippine society. The Filipino family is considered a treasured social institution in the Philippines. In general, Filipino families are bilaterally extended and residentially nuclear. However, the social contexts in which the Filipino families are embedded have changed rapidly over the past decade, more or less affected by the change in globalization and the Filipino people, possibly shaping the practice parents and children think about and relate with each other. For instance, growing numbers of families involve one or more parents leaving the house due to tragic occurrences and unfortunate reasons such as broken families and going abroad to work. Children thrive in stable and nurturing environments where they have a routine and know what to expect; therefore, assuring their well-being and healthy development provides a lens to a child's substantial and proper growth. However, changes might occur according to the child's development if certain negative occurrences might happen in their environment. Scholars such as Medina (2001) and Alampay (2014) have suggested that these changes might come with shifts in parenting beliefs and behaviors, affecting their development.

\subsection{Effects on Perceptions on Marital Partner, Marriage, and Family}

Child maltreatment has been associated with low social functioning in early and middle childhood. When presented with ambiguous social stimuli, maltreated children are more likely than other children to describe interpersonal relationships as threatening and painful (Ornduff, 2000) and to attribute hostile intentions toward social partners (Dodge et al., 1995). Maltreated children are more aggressive than their non-maltreated peers (Bolger, Patterson, \& Kupersmidt, 1998) and often avoid or withdraw from social interactions (Haskett \& Kistner, 1991). Adult males with histories of physical and sexual abuse are more likely than non-abused males to engage in violence toward intimate partners and family members (White \& Widom, 2003). Likewise, women with histories of child abuse are more likely than non-abused women to commit and receive abuse (White $\&$ Widom, 2003).

Available evidence suggests that individuals maltreated in childhood continue to experience problems in their relationships in adulthood. Moreover, when relationships are formed, women with childhood abuse histories are more likely than non-abused women to report dissatisfaction and marital disruption (i.e., separation/divorce) within their romantic partnerships (Fleming et al., 1999). Results also clearly show that physically abused schoolchildren are at greater risk for poor peer relationships than nonmaltreated classmates: in the classroom, they are at increased risk for lower social status, especially peer rejection; they receive fewer positive and more negative choices and so have less positive reciprocity in their relationships with classmates; their classmates perceive them as engaging in more harmful and fewer positive social behaviors (Salzinger et al., 1993). Distortions of social understanding, deriving from children's experience as victims or witnesses of family violence, might also be expected to mediate abused children's status among peers. The social group itself may play a role in perpetuating the same behavior that brought it about in the first place. In the critical domain of social relationships, avoidant social behavior and adaptational failure 
also seem problematic for abused children. Punishment of social approach, a typical contingency in abusive families (Burgess \& Conger, 1978), might well give rise to conditioned fear of anxiety, resulting in later generalized social avoidance. Consistent with this, abused children are more withdrawn and show more internalizing problem behaviors (Kaufman \& Cicchetti, 1989).

\section{Methodology}

\subsection{Research Design and Sampling}

This descriptive phenomenological qualitative study examined the abusive parent-child experiences of selected Filipino adolescents from low socioeconomic status intact families from Metro Manila. This study also described their social support system, coping mechanisms, and their perception of future marital partner, concept of marriage, and family.

Being a qualitative study, key informant interviews (KII) were conducted with the use of Zoom software. An in-depth interview guide was prepared as its data collection instrument.

The informants were selected through purposive non-probability sampling using the following criteria: 1 . Filipino adolescents aged 18 - 24 years old who experienced physical and verbal abuse were still a minor from one or both parents, 2 . from an intact family, 3. from low socioeconomic status, and 4. residing within Metro Manila.

\subsection{Data Gathering Instruments and Data Collection}

Using a phenomenological-qualitative methodological approach, an in-depth interview guide was used as data collection instrument (See Table 1. Data Collection Instrument Matrix).

Table 1. Matrix of Data Collection Instrument

\begin{tabular}{|l|l|}
\hline \multicolumn{1}{|c|}{ Sections } & \multicolumn{1}{c|}{ Variables and Indicators } \\
\hline Abusive Parent-Child Experiences & $\begin{array}{l}\text {-Types of Abusive Relationship } \\
\text { - Social Support Systems } \\
\text { - Coping Mechanisms }\end{array}$ \\
Effects on the Perception of & $\begin{array}{l}\text { - Future Marital Partner } \\
\text { - Concept of Marriage } \\
\text { - Concept of Family }\end{array}$ \\
\hline
\end{tabular}

The in-depth interview guide composed of a loose structure of open-ended questions intended to unpack their abusive parentchild experiences and its effects on their perceptions of their future marital partner, concept of marriage, and family. Informants were also asked regarding their experience of an abusive parent-child relationship, social support system, and coping mechanisms.

The researchers conducted the in-depth interviews with a licensed guidance counselor to ensure professional management of breakouts among informants triggered by the opening up of deep emotions during discussion.

\subsection{Data Analysis}

The researchers employed thematic analyses to illuminate and uncover the informants' abusive parent-child relationship encounters, such as the types or forms of physical and verbal abuse they experienced, their support system, coping mechanism, and their perceptions of their future partner in life, concept of marriage, and family.

\subsection{Ethical Considerations}

An informed consent form was provided in line with all the informants to ensure that anonymity and confidentiality will be assured. It covered essential information regarding the purpose of the study, duration of the interview, the use of alias or pseudo-name to maximize their anonymity, protection of their data, withdrawal from the interview or the study if they have doubts or felt offended during the conduct of the study. Also, as the topic was sensitive and may trigger negative emotions, the interviews were conducted, with their consent, with a licensed guidance counselor. 


\section{Results and Discussion}

\subsection{Profile of the Informants}

Table 2 presents the profile of the seven Filipino adolescent informants of this study. Two of the informants were males, while five were females. All of them encountered maltreatment from their mothers, while four disclosed abuse from both parents (I1, $13,15,17)$. Pseudo-names were used to protect the identity of the informants.

Table 2. Personal Characteristics of the Informants

\begin{tabular}{|c|c|c|c|c|}
\hline Informant & Pseudonym & Sex & Age & Abuser \\
\hline $\mathbf{I 1}$ & Jose & Male & 18 & Father \& Mother \\
\hline $\mathbf{1 2}$ & Eric & Male & 18 & Mother \\
\hline $\mathbf{1 3}$ & Angel & Female & 18 & Mother \& Mother \\
\hline $\mathbf{1 4}$ & Joy & Female & 19 & Father \& Mother \\
\hline $\mathbf{1 5}$ & Mika & Female & 18 & Mother \\
\hline $\mathbf{1 6}$ & Aly & Female & 18 & Father \& Mother \\
\hline $\mathbf{1 7}$ & Sophia & Female & 18 & \\
\hline
\end{tabular}

\subsection{Experience of Physical and Verbal of Abuses of the Informants}

In most cultures, parenting is seen as an integral social role with a significant influence on the lives of children and parents themselves (Alampay, 2014). However, in a family of low socioeconomic status, wherein the parent-child relationship is abusive, the child has to carry the pain that affects their psycho-emotional well-being (Ross et al.,1998). In such cases, children from low socio-economic status suffer from emotional and behavioral problems more frequently compared to children from better socioeconomic status. Abused children from low socio-economic status were found to manifest aggression and social withdrawal as well as anxiety and depression (Brooks-Gunn \& Duncan, 1997).

Any global approach to a parent-child abusive relationship must consider the distinct practices and standards for parenting behavior in the range of cultures worldwide (WHO, n.d.). Culture is a society's common fund of beliefs and behaviors and its concepts of how people should conduct themselves. Views on child-rearing across cultures might diverge to such an extent that agreement on abusive or neglectful methods may be complicated to reach, which is prevalent among the Philippine culture's discipline strategies. Filipino parents are not able to distinguish safe discipline from abuse. A study showed that mothers show more violence than fathers (Sumba \& Bwibo, 1993). However, another study showed that men are the most common perpetrators of life-threatening head injuries, abusive fractures, and other fatal injuries (Klevens et al., 2000). In the Philippines, the fathers are perceived as disciplinarians while the mothers are viewed as the significant protector, nurturant, and more involved in the child's academics (Alampay \& Jocson, 2011).

In the Philippines, mothers are labeled "noisy" and mostly into verbal scolding or disciplining, while the father is perceived as the physical disciplinarian. This study showed that mothers are more into abusive associations with their child in Filipino families of low socioeconomic status groups than the fathers. All of the informants experienced verbal and actual maltreatment from their mothers. Informants 2, 4, and 6 received physical and verbal abuse exclusively from their mothers. Looking deeply into the situation, the Filipino fathers are additionally seen as the providers and may regularly be away from home. Thus, mothers are usually with the children at home as she is tasked with child-rearing, disciplining in the father's absence, and "managing the home" (De La Cruz et al., 2001). The study negates the Philippines ' regularizing culture and assumptions wherein fathers perform the disciplining task in the Filipino household, exposing mothers to be more present and active in the harsh disciplining. Table 3 described the abuses suffered by the informants. This revealed how the home became an antagonistic place instead of being a place where they can find solace and be nurtured. 
The abuses experienced by the informants escalated into life-threatening encounters. Informant 4 has mentioned that her mother choked her while the parents of informant 3 would hit her with any objects available. Informant 6 was threatened with deadly things by her mother. Overall, all of the informants have been cursed at, belittled, and compared to degrading matters. These experiences are fundamentally scarring to one's development, more so when endured every day. Mothers were all identified to inflict immense physical and verbal abuses on the informants. While Informant 1 had experienced little physical abuse, his verbal abuse encounters were much more damaging. As a result, he became very cautious around his parents as he feared that he would experience physical and verbal abuse at any time. Mothers were mentioned by all to be involved in the parent-child abuse. This led to a complex family environment for the informants, considering that the mothers are expected to care more for the child and show disciplining through simple verbal remarks in the Philippine culture. At the same time, the fathers utilize threatening acts as the disciplinarian.

Table 3. Experiences of Physical and Verbal of Abuse by Adolescents from Low Socio-economic Family Status

\begin{tabular}{|c|l|l|}
\hline Informant & \multicolumn{1}{|c|}{ Physical Abuse } & \multicolumn{1}{c|}{ Verbal Abuse } \\
\hline $\mathbf{1 1}$ & "Minor hitting and pointing fingers at the forehead." & $\begin{array}{l}\text { "Shouting, Defamatory language, Uncontrollable } \\
\text { anger, and Palpable disdain." }\end{array}$ \\
\hline $\mathbf{1 2}$ & $\begin{array}{l}\text { "She would slap, spank and throw things at me and } \\
\text { bring out a knife because of anger." }\end{array}$ & $\begin{array}{l}\text { "She would curse, shout, gaslight, name-call, and } \\
\text { demean me." }\end{array}$ \\
\hline $\mathbf{1 3}$ & $\begin{array}{l}\text { "They throw, whack, sometimes slap and hit us using } \\
\text { any object." }\end{array}$ & $\begin{array}{l}\text { "They shout, curse, and compare us to different things } \\
\text { and people." }\end{array}$ \\
\hline $\mathbf{1 4}$ & $\begin{array}{l}\text { "She would slap, pull my hair, choke me, hit me with } \\
\text { an object, beat, and place me in constant fear." }\end{array}$ & $\begin{array}{l}\text { "She would use cursing, yelling, belittling, demeaning, } \\
\text { gaslighting, name-calling, and threatening to me." }\end{array}$ \\
\hline $\mathbf{1 6}$ & $\begin{array}{l}\text { "She would slap, punch, pinch, and pull my hair." } \\
\text { "She'd slap, push, punch, beat, and threaten us with }\end{array}$ & $\begin{array}{l}\text { "They would mostly compare curse, yell, and demean } \\
\text { me." }\end{array}$ \\
\hline $\mathbf{1 7}$ & $\begin{array}{l}\text { "They would slap, choke, pull my hair, kick, and } \\
\text { attempt to cause physical harm." }\end{array}$ & $\begin{array}{l}\text { "They would use derogatory names, curse at me, } \\
\text { threaten, belittle, and demean me. }\end{array}$ \\
\hline
\end{tabular}

Moreover, these parents may have difficulty separating child abuse from discipline. The encounters that the informants have faced are severe and significantly traumatizing. According to W.H.O, different cultures have different rules about what are acceptable parenting practices. Some researchers have suggested that views on child-rearing across cultures might diverge to such an extent that agreement on abusive or neglectful methods may be complicated to reach, which is observed and prevalent in Filipino culture, disciplining structures practices. According to Corso et al. (2018), it constitutes "crossing the line" from discipline to child abuse. This study has exposed mothers to be accountable for the physical and psychological scarring. Mothers are acknowledged as the support and the "light" of a home in a Philippine setting, and the study revealed an opposite representation of mothers from low socioeconomic families.

\subsection{Social Support System}

The study found that all the informants have received support from the extended family and non-family members (see Table 4).

Table 4. Social Support System of Informants

\begin{tabular}{|c|c|c|}
\hline Informant & \multicolumn{1}{|c|}{ Family } & Non-Family \\
\hline $\mathbf{I 1}$ & $\begin{array}{l}\text { ・ Grandparents } \\
\text { 'They show support by alleviating the situation; my } \\
\text { grandparents disagree regarding my mother's treatment } \\
\text { of me. " }\end{array}$ & $\begin{array}{l}\text { " Friends } \\
\text { "They help me forget and provide an atmosphere } \\
\text { that they have accepted and support me." }\end{array}$ \\
\hline
\end{tabular}




\begin{tabular}{|c|c|c|}
\hline 13 & $\begin{array}{l}\text { • Grandparents } \\
\text { "They do not judge and help me decide what I } \\
\text { should do." }\end{array}$ & $\begin{array}{l}\text { • Friends } \\
\text { "We always talk to each other. I do not open up } \\
\text { all the details, but they help me by being there." }\end{array}$ \\
\hline 14 & $\begin{array}{l}\text { • Grandparents } \\
\text { "They provide security, intervention, and safety to } \\
\text { me." }\end{array}$ & $\begin{array}{l}\text { • Friends } \\
\text { "They give advice and comfort me." }\end{array}$ \\
\hline 15 & $\begin{array}{l}\text { • Brother } \\
\text { "He listens and understands, which cools me off. He } \\
\text { buys food and says comforting words." }\end{array}$ & $\begin{array}{l}\text { • Friends } \\
\text { "They console me. They help me cope more } \\
\text { than my family members." }\end{array}$ \\
\hline 17 & $\begin{array}{l}\bullet \quad \text { Cousin } \\
\text { "My cousin always comforts me." }\end{array}$ & $\begin{array}{l}\text { - Friends } \\
\text { "I do not open up everything to my friends } \\
\text { because of the fear of being judged and judging } \\
\text { my family. However, they comfort me when I } \\
\text { open up certain things. }\end{array}$ \\
\hline
\end{tabular}

The extended family plays a key role in providing social support to the abused children. Six out of the seven informants revealed that the grandparents stood as the informants' family support system. When the mother is the abuser, the grandparent/s, being more established in terms of age and status in the family, can provide intervention during abusive encounters (Bautista et al., 2001) Looking at the cases of Informants 2, 4, and 6's wherein the abuser is the mothers, the grandparent/s intervene to manage the abuse. The peers or friends serve as the informant's non-relative support though limited to simple acts such as comforting and helping in different activities. During the interview, all the informants have expressed that a non-family support system gives them unconditional acceptance and solace, enabling them to cope better. The presence of social support enhances their personal resilience, given their condition. Their social support gives them inspiration and self-confidence (Bautista et al., 2001).

\subsection{Coping Mechanisms}

In this study, coping mechanisms were divided into two categories, specifically, problem-focused coping and emotion-focused coping. Problem-focused coping refers to the directed responses towards resolving the stressor, which deals with the realities of experienced stress. On the other hand, emotional-focused coping refers to coping with alleviating or denying the emotions that arise from the stressor's cause. However, the use of emotion-focused coping can be divided into positive or harmful (negative) coping strategies.

As demonstrated in Table 4, all informants use actions that involve communicating or utilizing emotions to seek support from others rather than seeking solutions to the stressor and altering the abusive situation. This may be because the victims cannot protect themselves from their parents. They are forced to use emotions as a means of lightening themselves due to the event, as opposed to speaking up and resolving the problem, which goes with the Philippine context, taking into account that answering towards the parents or guardians are perceived as an indication of disrespect that contains utter and dire consequences. Considering that their parents provide for their needs, they may be afraid that their parent/s may abandon them. The abusive parents take advantage of this culture in the Philippines to inflict abuse rather than proper discipline.

Moreover, these informants are hesitant to defend themselves, fearing that this may escalate the abuse. Subsequently, they have no choice but to seek support from others or keep it by themselves. In the current study, only one informant utilized the positive emotion-focused approach, while six informants used the harmful method, such as suppressing emotions, denial, and avoidance. Due to being subjected to abuse most of the time, informant 3 has resulted in smoking to release stress and fear. It is 
only possible that due to their traumatic and stressful experiences, most of the informants have resulted in harmful coping mechanisms. Despite being given a sound support system, their experiences are far more overwhelming. Thus, most victims of an abusive parent-child relationship result in negative coping strategies. According to Saikia (2017), sudden and dramatic disruptions can significantly impact and influence the development of the child's behavior and health, affecting their decisionmaking and relationships. This shows that these experiences partake in their growth and development due to the abusive encounters. Victims of abuse may result in harmful coping methods with sustaining themselves mentally and emotionally. Various elements must be considered with each victim of abuse. These components alone can significantly affect how they manage themselves and these traumatizing experiences.

Table 4. Coping Mechanisms used by the Informants

\begin{tabular}{|c|c|c|c|c|}
\hline & Problem-Focused & \multicolumn{2}{|c|}{ Emotion-Focused Coping } & \multirow[t]{2}{*}{ Actions } \\
\hline Informant & & $\begin{array}{l}\text { Positive Emotion- } \\
\text { Focused Coping }\end{array}$ & $\begin{array}{l}\text { Negative } \\
\text { Emotion-Focused } \\
\text { Coping }\end{array}$ & \\
\hline 11 & & & $\checkmark$ & $\begin{array}{l}\text { Suppression of Emotions, Avoidance, and } \\
\text { Denial }\end{array}$ \\
\hline 12 & & & $\checkmark$ & $\begin{array}{l}\text { Avoidance, Suppression of Emotions, and } \\
\text { Distraction from other activities }\end{array}$ \\
\hline 13 & & & $\checkmark$ & $\begin{array}{l}\text { Smoking, Suppression of Emotions, } \\
\text { Avoidance, and Denial }\end{array}$ \\
\hline 14 & & & $\checkmark$ & $\begin{array}{l}\text { Suppression of emotions, Avoidance, and } \\
\text { Forgetting }\end{array}$ \\
\hline 15 & & $\checkmark$ & & $\begin{array}{l}\text { Distraction from other activities, Talking to } \\
\text { friends and Eating comfort food. }\end{array}$ \\
\hline 16 & & & $\checkmark$ & $\begin{array}{l}\text { Avoidance, Suppression of emotions, and } \\
\text { Distraction from other activities }\end{array}$ \\
\hline 17 & & & $\checkmark$ & $\begin{array}{l}\text { Suppression of emotions, Avoidance, and } \\
\text { Cutting Classes }\end{array}$ \\
\hline
\end{tabular}

\subsection{Perceptions on Future Marital Partner, Concept of Marriage, and Family}

Table 5 displays parent-child abuse's impact on the informants' perceptions; they were asked about their future partners, marriage, and family perceptions. On their perception of a future marital partner, the informants' desired attributes are patient, support, and understanding. Informant 6's statement depicts positivity and high expectations for an ideal partner. Her answer exhibited an impact from her abusive parent-child experiences, considering that she wants someone who does not resort to violence. Overall, the informants have gained explicit inclinations to cease what they have experienced towards their future offspring/s.

Table 5. Informants' Perceptions of their Future Marital Partner, Concept of Marriage, and Family

\begin{tabular}{|c|l|l|l|}
\hline Informant & \multicolumn{1}{|c|}{ Marital Partner } & \multicolumn{1}{c|}{ Marriage } & Family \\
\hline $\mathbf{I 1}$ & $\begin{array}{l}\text { "Someone you will need } \\
\text { in the future." }\end{array}$ & $\begin{array}{l}\text { "Protects the family from harmful "My experiences gave me a better } \\
\text { influences and will keep the family } \\
\text { intact." }\end{array}$ & $\begin{array}{l}\text { outlook on how to respond shortly } \\
\text { when I have my own family." }\end{array}$ \\
\hline
\end{tabular}




\begin{tabular}{|c|c|c|c|}
\hline 12 & "Who can commit." & $\begin{array}{l}\text { "Marriage must be strong and a lasting } \\
\text { bond with my partner." }\end{array}$ & $\begin{array}{l}\text { "When I have children, I want them } \\
\text { to experience the opposite of what I } \\
\text { experienced." }\end{array}$ \\
\hline 13 & $\begin{array}{l}\text { "Who will protect and be } \\
\text { always open to } \\
\text { adjustment." }\end{array}$ & $\begin{array}{l}\text { "I would like to. However, I believe it is } \\
\text { not a must." }\end{array}$ & $\begin{array}{l}\text { "People that make you feel safe. As a } \\
\text { mother, I will never hurt my } \\
\text { children." }\end{array}$ \\
\hline 15 & $\begin{array}{l}\text { "Someone who will } \\
\text { understand and never } \\
\text { abandon you." }\end{array}$ & "Marriage is just a formality." & $\begin{array}{l}\text { "I don't want my future children to } \\
\text { experience the abuse." }\end{array}$ \\
\hline 17 & $\begin{array}{l}\text { "Just someone } \\
\text { supportive, and I can } \\
\text { lean on." }\end{array}$ & $\begin{array}{l}\text { "I believe that two people can love each } \\
\text { other without marriage. Right now, I do } \\
\text { not want to get married." }\end{array}$ & $\begin{array}{l}\text { "Someone who will understand and } \\
\text { support you." }\end{array}$ \\
\hline
\end{tabular}

Regarding their view of marriage, the informants' abusive parent-child relationship has taken a toll on their perception. Informants 3, 4, 5, and 7 pointed out that "marriage" is not necessary and not a must. However, in Informant 5, she stated that she does not believe that marriage is needed because her mother cheats. On the other hand, Informant 6 noted that marriage depends on whom she marries. This shows that factors during their experiences and development can quickly and significantly influence their perception of marriage. The informants have created a leaning on a better future marital relationship that will affect their marriage decision, depending on how they act as a partner-considering that these informants have experienced a very traumatic and disruptive parent-child relationship. They do not want what they experienced to happen to their future family. Informant 7's answer can be evidence considering that she believes that two people can love each other without getting married. The actions that her prospective marital partner will portray will be the deciding factor for Informant 7's in getting married to that specific person. Therefore, the informants' answers on marriage were heavily reliant on their ideal partners, as all of them firmly and specifically described their ideal partners.

It can also be exhibited that the informants' answers on family were heavily dependent on their ideal partners and marriage. The informants yearn for a stable relationship with their children if they do have to raise a family in the future. Informant 1 specified that his abusive encounters gave a better comprehension of how to respond towards his future family. As for Informant 6, she shared that she does not want to repeat her mom's same mistakes in raising her child. Given their abusive experiences, the informants have established specific characteristics for their families in the future. With the informants' perceptions being impacted by their negative experiences and beliefs, they have grounded themselves to have a stable, loving, accepting, and understanding future family. Their abusive encounters transformed their outlook on a natural family characteristic into an ideal one. Moreover, the data also showed that all informants have an enthusiastic family perspective, particularly on the family they may have in the future.

\section{Conclusion}

The study captured the abusive parent-child relationship experiences of seven Filipino adolescents from low socioeconomic status in Metro Manila. This study unpacked the experiences of children who suffered both forms of physical and verbal abuses, their social support, coping mechanism, and how these impacted their perceptions of their future marital partner, concept of marriage, and family. Surprisingly, the study unfurled a striking reality among families of low socio-economic status. The mothers expected to be the protector and nurturant of children ended up being the abuser in the family, setting imminent and traumatizing abusive experiences towards their children. With this, the abused adolescents have been dependent on their grandparents as their support system to provide the intervention needed to manage the abuse. Among the non-relatives, friends are a unique support system that the informants have, thinking they give an atmosphere complete of acceptance and understanding. The support that the informants receive from their peers dispels doubt, fear, and trauma. 
The study also examined the effects of abusive parent-child relationship experiences on the informants' perceptions of their future marital partner, marriage and family. Overall, they emphasized that the decision to venture into marriage and form a family rely heavily upon the partner's qualities. The majority hopes and holds a positive perspective of their future partner and family. However, the informants' idea to set forth to a marriage has been impacted by their experiences. Despite the coping strategies and support systems, the informants' negative position to pursuing marriage. The actions committed by their parents are a huge deciding factor in how they perceive their marriage. The informants' parents' abusive and unjust behavior is visible to these children's minds and that marriage is not a must.

A further understanding can be used as a reference for future researchers. It would provide substantial insights into promotion using an in-depth phenomenological and qualitative approach in a critical informant interview research. The study can serve as a guide for a quantitative approach to define the extent and level of abuse for other researchers, considering that the research focuses on the perception of future marital partner, the concept of marriage, and the idea of a family from an abusive parentchild relationship in terms of physical and verbal abuse, social support these children possess, and coping mechanism that they use. They may also use the study as a prefix in expounding similar topics and subjects, such as how it can affect their relationships with peers and how these children may interact with their parents from a long-term perspective.

Funding: This research received no external funding

Acknowledgment: The researchers would like to express their sincere gratitude and appreciation to the following: Ms. Maureen Antonette Ledesma for providing the protocols in conducting the critical informant interviews; all the informants involved in the study for their willing participation in this study; the researchers' parents who have imparted ample time, effort, and knowledge in providing notes to making the research output better, and to the DLSU Integrated School SHS unit for the support to complete the study.

Conflicts of Interest: The authors declare no conflict of interest.

\section{References}

[1] Alampay, L. P. (2014). Parenting in the Philippines. In Parenting across cultures (pp. 105-121). Springer, Dordrecht.

[2] Alampay, L. P., \& Jocson, M. R. M. (2011). Attributions and Attitudes of Mothers and Fathers in the Philippines. Parenting, 11(2-3), 163-176. https://doi.org/10.1080/15295192.2011.585564

[3] Ammerman, R.T., Cassisi, J.E., Hersen, M., \& Van Hasselt, V.B. (1986). Consequences of physical abuse and neglect in children. Clinical Psychology Review, 6, 291-310.

[4] Bardi, M., \& Borgognini-Tari, S. M. (2001). A survey of parent-child conflict resolution: intrafamily violence in Italy. Child Abuse \& Neglect, 25:839-853.

[5] Bautista, Roldan, \& Garces-Bacsal. (2001). The Abuse of Filipino Children. Retrieved December 15, 2020, from https://childhub.org/en/system/tdf/library/attachments/bautista_ungated_abuse_of_filipino_children_1.pdf?file=1\&type=node\&id=16940

[6] Bennett, N., \& O'Donohue, W. (2014). The construct of grooming in child sexual abuse: Conceptual and measurement issues. Journal of child sexual abuse, 23(8), 957-976.

[7] Besharov, D.J. (1990). Recognizing child abuse: A guide for the concerned. New York: Free Press.

[8] Bierman, A. (2005). The effects of childhood maltreatment on adult religiosity and spirituality: Rejecting God the Father because of abusive fathers?. Journal for the Scientific Study of Religion, 44(3), 349-35

[9] Bolger, K. E., Patterson, C. J., \& Kupersmidt, J. B. (1998). Peer Relationships and Self-Esteem among Children Who Have Been Maltreated. Child Development, 69(4), 1171. https://doi.org/10.2307/1132368

[10] Brendgen, M., Wanner, B., \& Vitaro, F. (2006). Verbal abuse by the teacher and child adjustment from kindergarten through grade 6. Pediatrics, 117, 1585-1598. http://dx.doi.org/10.1542/peds.2005-2050

[11] Brooks-Gunn, J., \& Duncan, G. (1997). The Effects of Poverty on Children. The Future of Children, 7(2), 55-71. https://doi.org/10.2307/1602387

[12] Bross, D.C., et al. (2000). World perspectives on child abuse: the fourth international resource book. Denver, CO, Kempe Children's Center, University of Colorado School of Medicine.

[13] Browne, D. (2002). Coping alone: Examining the prospects of adolescent victims of child abuse placed in foster care. Journal of Youth and Adolescence, 31(1), 57-66.

[14] Burgess, R. L., \& Conger, R. D. (1978). Family Interaction in Abusive, Neglectful, and Normal Families. Child Development, $49(4), 1163$. https://doi.org/10.2307/1128756

[15] Carlo, G., Mestre, M. V., McGinley, M. M., Samper, P., Tur, A., \& Sandman, D. (2012). The interplay of emotional instability, empathy, and coping on prosocial and aggressive behaviors. Personality and Individual Differences, 53(5), 675-680.

[16] Che Noh, Che Hasniza \& Talaat, Wan. (2012). Verbal Abuse on Children: Does It Amount to Child Abuse under the Malaysian Law?. Asian Social Science. 8. 10.5539/ass.v8n6p224.

[17] Compas, B. E., Connor, J. K., Saltzman, H., Thomsen, A. H., \& Wadsworth, M. (1999). Getting specific about coping: Effortful and involuntary responses to stress in development. Soothing and stress, 229-256.C

[18] Corso, P. S., Edwards, V. J., Fang, X., \& Mercy, J. A. (2008). Health-related quality of life among adults who experienced maltreatment during childhood. American journal of public health, 98(6), 1094-1100. 
[19] De la Cruz, M. T., Protacio, E., Balanon, F., Yacat, J., \& Francisco, C. (2001). Trust and power: Child abuse in the eyes of the child and the parent. Manila, the Philippines: UP CIDS-Psychosocial Trauma and Human Rights Program.

[20] Dodge, K. A., Pettit, G. S., Bates, J. E., \& Valente, E. (1995). Social information-processing patterns partially mediate the effect of early physical abuse on later conduct problems. Journal of Abnormal Psychology, 104(4), 632-643. https://doi.org/10.1037/0021-843x.104.4.632

[21] Dolev-Cohen, M., Ricon, T., \& Levkovich, I. (2020). \# WhylDidntReport: Reasons why young Israelis do not submit complaints regarding sexual abuse. Children and Youth Services Review, 105044.

[22] Egeland, B. (1993). A history of abuse is a significant risk factor for abusing the next generation. In: Gelles RJ, Loseke DR, eds. Current controversies on family violence. Thousand Oaks, CA, Sage: 197-208.

[23] Elliott, A. N., \& Carnes, C. N. (2001). Reactions of nonoffending parents to the sexual abuse of their child: A review of the literature. Child maltreatment, 6(4), 314-331.

[24] Evans, Gary W., Jeanne Brooks-Gunn, and Pamela Kato Klebanov. (2011). Stressing Out the Poor: Chronic Physiological Stress and the Income-Achievement Gap. Community Investments 23(2): 22-27.

[25] Fleming, J., Mullen, P. E., Sibthorpe, B., \& Bammer, G. (1999). The long-term impact of childhood sexual abuse in Australian women. Child Abuse \& Neglect, 23(2), 145-159. https://doi.org/10.1016/s0145-2134(98)00118-5

[26] Garbarino, J., Guttman, E., \& Seeley, J.W. (1986). The Psychologically Battered Child: Strategies or Identification, Assessment, and Intervention. In Esteban, E.J. (Ed.), Parental Verbal Abuse: Culture-Specific Coping Behavior of College Students in the Philippines. Child Psychiatry and Human Development, 36, 863-870.

[27] Grady, J. (2003). Stop Verbal Abuse. Houston: Therapia Publishing.

[28] Guanzon, M. V. (2012). A Primer on Republic Act No. 9262 the Anti-Violence against Women and their Children (ANTI-VAWC) Act of 2004 and Barangay Protection Order (BPO). U.P. Law Complex, 973,971, 15,04 37, 3

[29] Haskett, M. E., \& Kistner, J. A. (1991). Social Interactions and Peer Perceptions of Young Physically Abused Children. Child Development, 62(5), 979. https://doi.org/10.2307/1131147

[30] Hunter, R. S., \& et al. (1978). Antecedents of child abuse and neglect in premature infants: a prospective study in a newborn intensive care unit. Pediatrics, 61:629-635.

[31] Jackson, Y., Huffhines, L., Stone, K. J., Fleming, K., \& Gabrielli, J. (2017). Coping styles in youth exposed to maltreatment: Longitudinal patterns reported by youth in foster care. Child abuse \& neglect, 70, 65-74.

[32] Kalichman, S.C. (1993). Mandated reporting of suspected child abuse: Ethics, law, and policy. Washington, DC: American Psychological Association.

[33] Kaufman, J., \& Cicchetti, D. (1989). Effects of maltreatment on school-age children's socioemotional development: Assessments in a daycamp setting. Developmental Psychology, 25(4), 516-524. https://doi.org/10.1037/0012-1649.25.4.516

[34] Kelly, J.A. (1983). Treating child-abusive families: Intervention based on skills training principles. New York: Plenum Press.

[35] Keller, K., \& Fox, R.A. (2009). Toddlers with developmental delays and challenging behaviors. Early child development \& Care, 179, 87-92. http://dx.doi.org/10.1080/03004430600987126

[36] Klevens J., Bayo'n, M. C., \& Sierra, M. (2000). Risk factors and the context of men who physically abuse in Bogota', Colombia. Child Abuse \& Neglect, 24:323-332.

[37] Koçtürk, N., \& Bilginer, S. Ç. (2020). Adolescent sexual abuse victims' levels of perceived social support and delayed disclosure. Children and Youth Services Review, Volume 118, 105363, ISSN 0190-7409. Retrieved from https://doi.org/10.1016/j.childyouth.2020.105363.

[38] Kogan, S. M. (2005). The role of disclosing child sexual abuse on adolescent adjustment and revictimization. Journal of Child Sexual Abuse, 14(2), 25-47.

[39] Lansford, J. E., Alampay, L. P., Al-Hassan, S., Bacchini, D., Bombi, A. S., Bornstein, M. H., ... \& Oburu, P. (2010). Corporal punishment of children in nine countries as a function of child gender and parent gender. International Journal of pediatrics.

[40] Li, M., D'arcy, C., \& Meng, X. (2016). Maltreatment in childhood substantially increases the risk of adult depression and anxiety in prospective cohort studies: systematic review, meta-analysis, and proportional attributable fractions. Psychological medicine, 46(4), 717-730.

[41] Medina, B. (2001). The Filipino family (2nd ed.). Quezon City: University of the Philippines Press.

[42] Mejia, A., Calam, R., \& Sanders, M. R. (2012). A review of parenting programs in developing countries: opportunities and challenges for preventing emotional and behavioral difficulties in children. Clinical child and family psychology review, 15(2), 163-175.

[43] National Center on Child Abuse and Neglect. (1988). Study of national incidence and prevalence of child abuse and neglect: 1986. Washington, DC: U.S. Department of Health and Human Services.

[44] National Research Council. (1993). Understanding child abuse and neglect. Washington, DC, National Academy of Sciences Press, 7.

[45] Ornduff, S. (2000). Childhood maltreatment and malevolence Quantitative research findings. Clinical Psychology Review, 20(8), 997-1018. https://doi.org/10.1016/s0272-7358(99)00021-5

[46] Purdue University. (n.d.). What is a family?. Retrieved from https://www.purdue.edu/hhs/hdfs/fii/wpcontent/uploads/2015/07/s_wifis01c02.pdf

[47] Rerkswattavorn, C. \& Chanprasertpinyo, W. (2019). Prevention of child physical and verbal abuse from traditional child discipline methods in rural Thailand, Heliyon. Volume 5, Issue 12, e02920, ISSN 2405-8440. https://doi.org/10.1016/j.heliyon.2019.e02920.

[48] Ross C. \& Blanc H. (1998). Parenting stress in mothers of young children with an oppositional defiant behavior disorder and other severe behavior problems. Child Study Journal; 28:93-110.

[49] Saikia, R. (2017). Broken family: Its causes and effects on the development of children. International journal of applied research, 3(2), 445448.

[50] Salzinger, S., Feldman, R. S., Hammer, M., \& Rosario, M. (1993). The Effects of Physical Abuse on Children's Social Relationships. Child Development, 64(1), 169. https://doi.org/10.2307/1131444

[51] Seiffge-Krenke, I., \& Klessinger, N. (2000). Long-term effects of avoidant coping on adolescents' depressive symptoms. Journal of youth and adolescence, 29(6), 617-630.

[52] Shonkoff, Jack P., and Andrew S. Garner. (2011). The Lifelong Effects of Early Childhood Adversity and Toxic Stress. Pediatrics 129: $232-46$. 
[53] Spillane-Grieco, E. (2000). From parent verbal abuse to teenage physical aggression?. Child and Adolescent Social Work Journal, 17, 411-430. http://dx.doi.org/10.1023/A:1026427710320

[54] Sumba, R. O. \& Bwibo, N. O. (1993). Child battering in Nairobi, Kenya. East African Medical Journal, 70:688-692

[55] The U.S. Centers for Disease Control and Prevention. (n.d.). About the CDC-Kaiser ACE Study |Violence Prevention|Injury Center|CDC. Retrieved 6 August 2020, from https://www.cdc.gov/violenceprevention/acestudy/about.html

[56] Theodore, A. D. \& Runyan, D. K. (1999). A medical research agenda for child maltreatment: negotiating the next steps. Pediatrics, 104:168177

[57] Ullman, S. E. (2002). Social reactions to child sexual abuse disclosures: A critical review. Journal of child sexual abuse, 12(1), 89-121.

[58] US Department of Health and Human Services; US Department of Education; US Department of Justice. (2001). Report of the Surgeon General's Conference on Children's Mental Health: A National Action Agenda. American Journal of Health Education, 32(3), 179-182. https://doi.org/10.1080/19325037.2001.10603461

[59] Vachss, A. (1994). You Carry the Cure in Your Own Heart. Parade Magazine, August 28. Retrieved 20/3, 2009, from http://www.vachss.com/av_dispatches/disp_9408_a.html

[60] VanMeter, F., Handley E. D., \& Cicchetti D. (2020). The role of coping strategies in the pathway between child maltreatment and internalizing and externalizing behaviors. Child Abuse \& Neglect, Volume 101, 104323, ISSN 0145-2134. Retrieved from https://doi.org/10.1016/j.chiabu.2019.104323.

[61] White, H. R., \& Widom, C. S. (2003). Intimate partner violence among abused and neglected children in young adulthood: The mediating effects of early aggression, antisocial personality, hostility and alcohol problems. Aggressive Behavior, 29(4), 332-345. https://doi.org/10.1002/ab.10074

[62] Wolfe, D.A. (1988). Child abuse and neglect. In E.J. Mash \& L.G. Terdal (Eds.), Behavioral assessment of childhood disorders (2nd ed., pp. 627-666). New York: Guilford Press.

[63] World Health Organization. (n.d.). Child abuse and neglect by parents and other caregivers. Retrieved 17 August 2020, from https://www.who.int/violence_injury_prevention/violence/global_campaign/en/chap3.pdf Zununegui, M. V., Morales, J. M., \& Martinez, V. (1997). Child abuse: socioeconomic factors and health status. Anales Espanoles de Pediatria, 47,33-41. 